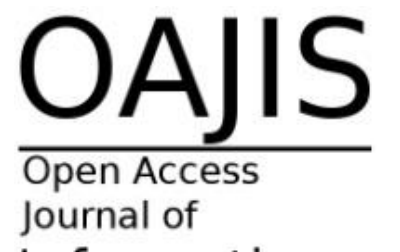

Information

Systems

is.its.ac.id/pubs/oajis/


Inspirasi Profesional Sistem Informasi

\section{People}

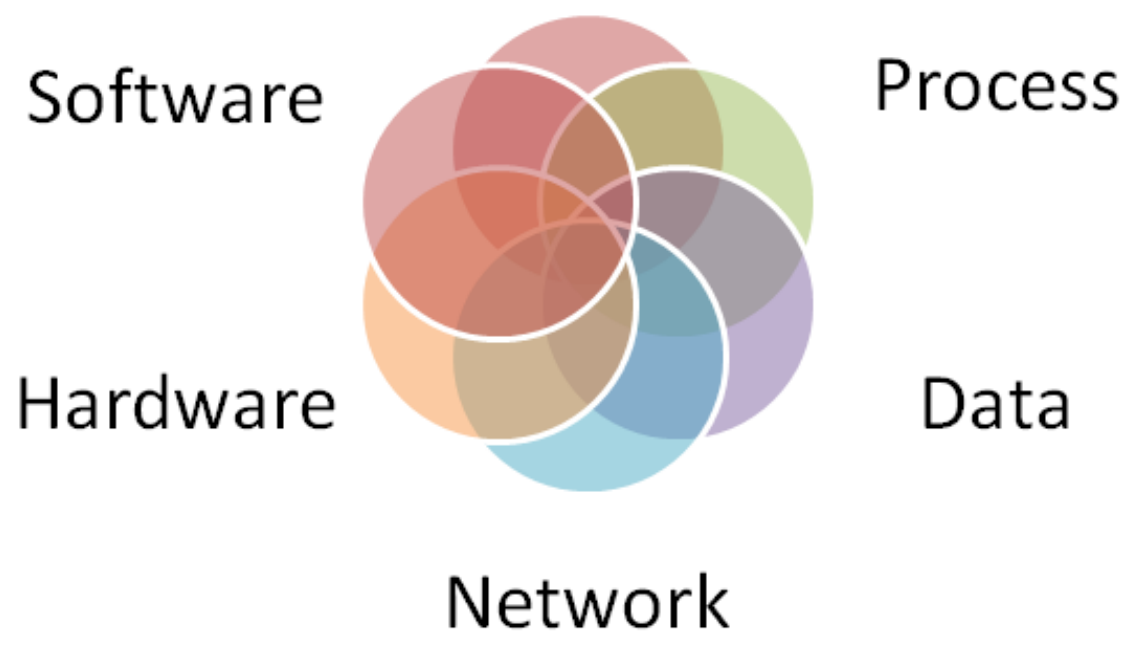


OAJIS

Journal of

Information

Systems

is.its.ac.id/pubs/oajis/

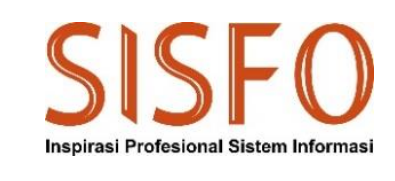

Jurnal Sisfo Vol. 08 No. 02 (2019) i-ii

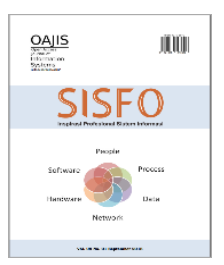

\section{Pimpinan Redaksi}

Faizal Mahananto

\section{Dewan Redaksi}

Eko Wahyu Tyas Darmaningrat

Amna Shifia Nisafani

Arif Wibisono

Rully Agus Hendrawan

\section{Tata Pelaksana Usaha}

\section{Achmad Syaiful Susanto}

Rini Ekowati

\section{Sekretariat}

Departemen Sistem Informasi - Fakultas Teknologi Informasi dan Komunikasi

Institut Teknologi Sepuluh Nopember (ITS) - Surabaya

Telp. 031-5999944 Fax. 031-5964965

Email: editor@jurnalsisfo.org

Website: http://jurnalsisfo.org

Jurnal SISFO juga dipublikasikan di Open Access Journal of Information Systems (OAJIS)

Website: http://is.its.ac.id/pubs/oajis/index.php 
OAJIS

Journal of

Information

Systems

is.its.ac.id/pubs/oajis/

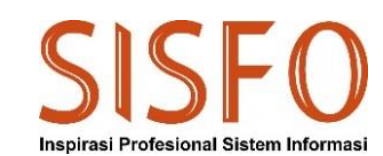

Jurnal Sisfo Vol. 08 No. 02 (2019) i-ii

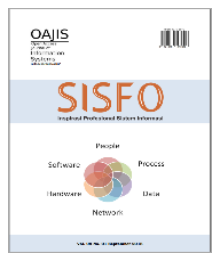

\section{Mitra Bestari}

Satria Fadil Persada, S.Kom., M.BA., Ph.D. (Institut Teknologi Sepuluh Nopember)

Sholiq, S.T., M.Kom., M.SA. (Institut Teknologi Sepuluh Nopember)

Nur Aini Rakhmawati, Ph.D. (Institut Teknologi Sepuluh Nopember)

Retno Aulia Vinarti, Ph.D. (Institut Teknologi Sepuluh Nopember)

Leon Andretti Abdillah, S.Kom., M.M. (Universitas Bina Darma)

Radityo Prasetianto W, S.Kom., M.Kom. (Institut Teknologi Sepuluh Nopember) 
OAJIS Journal of

Information

Systems

is.its.ac.id/pubs/oajis/

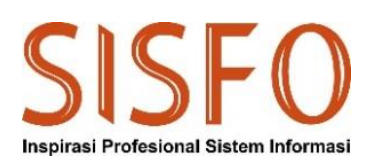

Jurnal Sisfo Vol. 08 No. 02 (2019) iii

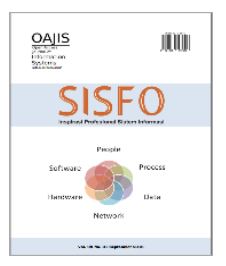

\section{Daftar Isi}

Evaluasi Kerangka Kerja Perencanaan Keberlangsungan Bisnis pada PT. Lotte Chemical Titan Nusantara

Mochammad Ikmal Amirullah, Apol Pribadi Subriadi......

ShopVis: Visualisasi Interaktif Persebaran Toko Daring di Indonesia Menggunakan Crowdsourced Data

Ruktin Handayani, Mohammad Arif Rasyidi. 99

Blended Learning dari Perspektif Para Guru Sekolah di Pondok Pesantren

Ahmad Muklason, Faizal Mahananto, Wiwik Anggraeni, Arif Djunaidy, Edwin Riksakomara .....

Pembuatan Prosedur dan Formulir Service Desk Pemerintahan Kota Madiun Berdasarkan ITIL V3

Zulaikah Effendi, Anisah Herdiyanti, Tony Dwi Susanto.

Rancang Bangun Dashboard dan Visualisasi Data Kickstarter dengan Pendekatan Business Intelligence

Irmasari Hafidz, Achmad Mirfak, Anisah Azhari, Aufar Ilham Adianto, Berry Humaidi Fuad, M. Ihsan Farabi .... 
Halaman ini sengaja dikosongkan 


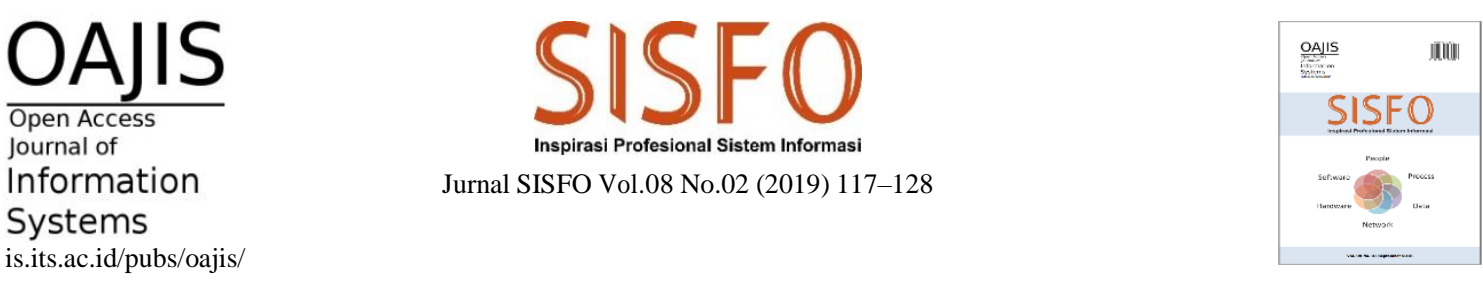

\title{
Pembuatan Prosedur dan Formulir Service Desk Pemerintahan Kota Madiun Berdasarkan ITIL V3
}

\author{
Zulaikah Effendi, Anisah Herdiyanti*, Tony Dwi Susanto \\ Departemen Sistem Informasi, Fakultas Teknologi Informasi dan Komunikasi, Institut Teknologi Sepuluh Nopember
}

\begin{abstract}
The Government of Madiun City is committed to apply Smart City concept by implementing Madiun Service Desk (MSD) to support e-government. However, the implementation of MSD application is not yet equipped with an operational standard for delivering information technology (IT) services to the consumers. Meanwhile, the IT services are handled by a Service Desk who ensures that the service levels are adhered, and requests are fulfilled. This research focuses on the development of standard operating procedures (SOPs), including procedures and forms to support their operations. Prior to the development of the SOPs, an information gathering was performed to understand the landscape of Service Desk. Then, a gap analysis was conducted based on the landscape and the standardized operations according to ITIL V3. The results from the research includes 4 (four) procedures, and 8 (eight) forms that has been validated by Service Desk in the Madiun City.
\end{abstract}

Keywords: Procedure, Form, Service Desk, ITIL V3

\begin{abstract}
Abstrak
Pemerintah Kota Madiun saat ini kian berbenah menuju Smart City dengan menerapkan Madiun Service Desk (MSD) yang mendukung Sistem Pemerintahan Berbasis Elektronik (SPBE). Namun sayangnya penerapan tersebut belum diiringi dengan standarisasi operasional layanan TI yang dikelola oleh Service Desk. Tugas pokok fungsi tersebut memastikan bahwa operasional layanan TI berjalan sesuai dengan tingkat layanan, dan memenuhi permintaan pengguna. Penelitian ini berfokus kepada standarisasi operasional layanan TI dengan menyusun prosedur dan formulir yang dapat digunakan Service Desk dalam menjalankan tugasnya dengan dukungan aplikasi MSD. Sebelum prosedur dan formulir disusun, penggalian dilakukan terhadap kondisi kekinian pengelolaan operasional layanan oleh Service Desk. Selanjutnya, analisis kesenjangan dilakukan terhadap kondisi kekinian dan kondisi mendatang dengan mencau pada operasional layanan TI terstandar, yaitu ITIL V3. Penelitian ini menghasilkan luaran berupa prosedur dan formulir, diantaranya 4 (empat) Standard Operating Procedure - SOP, dan 8 (delapan) formulir; yang telah diverifikasi dan validasi kepada fungsi Service Desk Pemerintah Kota Madiun.
\end{abstract}

Kata kunci: Prosedur, Formulir, Service Desk, ITIL V3

(C) 2019 Jurnal SISFO.

Histori Artikel: Disubmit 25-01-2019; Direvisi 30-01-2019; Diterima 31-01-2019; Tersedia online 31-01-2019

${ }^{*}$ Corresponding Author

Email address: anisah@ is.its.ac.id (Anisah Herdiyanti)

https://doi.org/10.24089/j.sisfo.2019.01.004 


\section{Pendahuluan}

Pemerintahan Kota Madiun sekarang ini sedang membentuk e-government yang handal menuju smart city dengan melakukan integrasi untuk tiga aplikasi di bidang pemerintah yaitu $e$-budgeting, e-planning dan $e$ kontrak [1]. Sementara itu penerapan e-government tersebut perlu diiringi dengan penanganan masalah dan permintaan layanan teknologi informasi. Untuk dapat menyediakan layanan yang diinginkan pengguna dan melakukan pengelolaan terhadap layanannya, pemerintah Kota Madiun harus memiliki layanan Service Desk yang menyediakan pusat operasional layanan kepada pengguna. Lebih jauh lagi, inisiasi penggalian data awal menunjukkan bahwa pemerintah Kota Madiun belum mempunyai layanan Service Desk untuk melayani seluruh pengguna layanan TI.

Selama ini pengguna yang mengalami masalah terkait layanan TI akan langsung menghubungi bagian staf TI. Akan tetapi, staf TI belum melakukan pencatatan terkait masalah maupun permintaan pengguna, sehingga mengakibatkan tidak diketahui akar penyebab permasalahan yang dapat menyebabkan masalah tersebut akan terulang kembali. Dalam mendukung aktivitas pengelolaan layanan TI tersebut, maka pemerintah Kota Madiun membutuhkan layanan Service Desk guna memastikan bahwa masalah yang dilaporkan pengguna menerima bantuan sesuai dengan jangka waktu penanganan yang telah ditentukan. Oleh karenanya, dibutuhkan layanan Service Desk yang bertugas untuk melakukan penanganan masalah dan pemenuhan permintaan pada sebuah layanan TI [2] apabila pengguna memiliki masalah terkait layanan TI yang digunakan, pengguna dapat menghubungi Service Desk untuk meminta bantuan terkait solusi penanganan masalah layanan TI yang dilaporkan oleh pengguna. Terlebih jauh lagi, pemerintah Kota Madiun juga masih belum memiliki standard operating procedure (SOP) untuk pengelolaan layanan TI, apabila tidak ada SOP maka tidak ada prosedur yang terstandar sehingga mengakibatkan ketidakjelasan dalam aktivitas dari proses yang dijalankan.

Standard operating procedure (SOP) diartikan sebagai pedoman tertulis yang berisikan mengenai apa yang diharapkan dan dibutuhkan oleh pegawai dalam membantu aktivitas yang dikerjakan. SOP sangatlah penting bagi organisasi karena memiliki beberapa manfaat salah satunya untuk menstandarisasi aktivitas yang dikerjakan dalam mendeskripsikan dan mendokumentasikan harapan kinerja yang digunakan sebagai panduan untuk memberikan pelatihan atau pengarahan kepada para pegawai [3]. Fakta di lapangan menunjukkan bahwa pertama, pemerintah Kota Madiun masih belum mempunyai SOP terkait penyelesaian masalah, permintaan layanan atau hak akses sehingga munculnya beberapa masalah diantaranya yang pertama mengenai alur prosedur dalam penyelesaian masalah, akses, dan permintaan. Fakta kedua menunjukkan bahwa tidak ada kebijakan yang mengatur dalam pengelolaan masalah, permintaan dan akses pengguna layanan TI. Idealnya, setiap organisasi harus memiliki SOP guna mendetailkan suatu proses kerja yang harus dilakukan atau diikuti dalam sebuah organisasi [4].

Penelitian ini berfokus kepada penyusunan SOP mencakup prosedur dan formulir untuk Service Desk. Penyusunan dilakukan mengacu kepada hasil analisis kesenjangan dengan melihat kondisi kekinian dan kondisi harapan yang disesuaikan dengan kondisi ideal berdasarkan kerangka kerja ITIL V3. Proses-proses yang digunakan dalam siklus service operation diantaranya: proses incident mangement, problem management, request fulfillment, dan access management. Selanjutnya pengujian dilakukan untuk memvalidasi SOP yang dibuat.

\section{Tinjauan Pustaka/Penelitian Sebelumnya}

Tinjauan pustaka digunakan sebagai dasar pengerjaan penelitian ini. Tinjauan pustaka dari penelitian adalah sebagai berikut. 


\subsection{Manajemen Layanan Teknologi Informasi}

Manajemen Layanan Teknologi Informasi (Information Technology Service Management) merupakan layanan teknologi informasi yang lebih mengacu pada implementasi dan manajemen kualitas layanan TI dalam memenuhi kebutuhan bisnis. Manajemen Layanan Teknologi Informasi dilakukan oleh penyedia jasa TI melalui people, process, and information technology [5]. Sedangkan menurut STQC (Government of India), menyebutkan bahwa manajemen layanan teknologi informasi mengarah kepada seluruh aspek manajerial dalam bisnis TI, termasuk model untuk perencanaan (plan), mendukung (support), menyampaikan (delivery), keamanan dan infrastruktur (security and infrastructure) yang dibutuhkan untuk penyedia layanan kualitas pelanggan [6]. Tujuan Manajemen Layanan Teknologi Informasi bagi suatu organisasi yaitu memaksimalkan layanan TI dengan melakukan pengelola layanan yang terstruktur sehingga dapat mencapai tujuan bisnis. Dengan adanya penerapan manajemen layanan TI yang baik dan terdokumentasi, maka organisasi akan mempunyai sebuah panduan untuk menyediakan layanan sesuai dengan standart kualitas yang telah ditetapkan.

\subsection{Service Desk}

Service desk merupakan single point of contact dari sekumpulan orang-orang atau tim yang berperan sebagai tempat komunikasi antara pengguna dan penyedia layanan dalam menangani sebuah permasalahan dan permintaan pada organisasi tertentu [7].

\subsection{Service Operation pada ITIL V3}

Service Operation merupakan tahapan dari lifecycle yang mencakup kegiatan operasional harian dalam pengelolaan layanan TI. Tujuan dari service operation adalah mencapai efesiensi dan efektifitas dalam mendukung dan menyediakan layanan TI untuk memastikan value kepada pengguna dan penyedia layanan. Termasuk dalam menyelesaikan kegagalan layanan, memperbaiki masalah, memenuhi permintaan layanan, dan melaksanakan tugas-tugas operasional secara rutin [8].

Berikut ini merupakan beberapa proses yang dilakukan di dalam Service Operation:

1) Event Management

Merupakan proses yang bertujuan untuk memastikan bahwa layanan TI yang berjalan selalu dimonitor.

2) Incident management

Merupakan proses yang bertujuan untuk mengelola insiden layanan TI agar layanan TI dikembalikan dalam keadaan semula (pulih) kepada pengguna secepat mungkin tanpa perlu menangani akar penyebab masalah.

3) Problem management

Merupakan proses yang bertujuan untuk mengelola akar masalah dari sebuah insiden layanan TI agar insiden yang sama tidak terulang kembali. Sehingga dapat meminimalkan dampak dari insiden yang tidak dapat dicegah.

4) Request fulfillment

Merupakan proses yang bertujuan untuk memenuhi permintaan pengguna layanan TI diluar dari laporan insiden layanan TI. Seperti permintaan untuk mengubah password atau permintaan informasi.

5) Access management

Merupakan proses yang bertujuan untuk memberikan hak akses kepada pengguna layanan TI yang berhak mendapatkan akses tersebut dan mencegah akses bagi pengguna yang tidak berwenang.

Pada pembuatan layanan Service Desk pemerintah Kota Madiun lebih terfokus pada empat proses yang dilakukan yaitu Incident management, Problem management, Request fulfillment, dan Access management. Penelitian sebelumnya telah mendiskusikan pembuatan SOP di studi kasus yang berbeda 
diantaranya Wicaksana et.al [9] yang membangun SOP untuk manajemen akses di Bina Program Kota Surabaya; Rizky et.al [10] yang membangun SOP untuk pengelolaan insiden di Bina Program Kota Surabaya.

\subsection{Standard Operating Procedure (SOP)}

Standard Operating Procedure (SOP) merupakan sebuah instruksi tertulis yang mendokumentasikan kegiatan rutin atau berulang yang diikuti oleh sebuah organisasi [11]. Menurut Atmoko, SOP merupakan sebuah pedoman atau acuan untuk melaksanakan tugas pekerjaan sesuai dengan fungsi dan alat penilaian kinerja berdasarkan indikator teknis, administratif dan prosedural sesuai dengan tata kerja, prosedur kerja, dan sistem kerja dalam suatu unit kerja terkait [12]. Sedangkan menurut Budiharjo, SOP adalah dokumen tertulis yang mengatur proses atau prosedur untuk dijadikan standar dalam palaksanaan tugas dan tanggung jawab organisasi [13].

Dapat disimpulkan bahwa SOP merupakan serangkaian panduan yang disusun secara sistematis mengenai proses, tugas, dan peran dari masing-masing individu maupun kelompok dalam menjalankan kegiatan sehari-hari di suatu organisasi. Namun, untuk analisis kesenjangan yang digunakan menggunakan analisis proses dalam melakukan pengelolaan layanan TI di pemerintah Kota Madiun.

\section{Metodologi}

Metodologi penelitian merupakan acuan yang dibuat peneliti dalam mengerjakan penelitian agar menjadi terstruktur. Gambar 1 menunjukkan langkah-langkah dalam penelitian, diantaranya: 1) mengumpulkan data kondisi terkini mengenai Service Desk di pemerintah Kota Madiun; 2) menganalisis kesenjangan antara kondisi terkini dan kondisi harapan sesuai standar ITIL V3; 3) menyusun SOP beserta formulirnya; 4) memverifikasi dan memvalidasi prosedur dan formulir melalui pengujian; serta 5) menyusun dokumen akhir.

\section{Hasil dan Pembahasan}

Bagian ini menjelaskan hasil yang didapatkan dari penelitian ini, dan pembahasan secara keseluruhan yang didapatkan dari penelitian. Berikut ini merupakan hasil dan pembahasan sebagai berikut:

\subsection{Tahap Pengumpulan Data dan Informasi}

Merupakan tahapan dimana penulis melakukan pengumpulan data dan informasi yang akan digunakan untuk bahan analisis dan penyusunan dokumen prosedur dan formulir. Pengumpulan data dan informasi berdasarkan kondisi kekinian dilakukan dengan metode yaitu wawancara, observasi yang dilakukan secara langung dan studi dokumen.

1) Wawancara

Wawancara dilakukan dengan mengajukan pertanyaan dari daftar interview protocol dan menyebarkan kuesioner untuk mengetahui kondisi kekinian dan kondisi yang diharapkan pada organisasi. Wawancara akan dilakukan secara langsung kepada pihak narasumber terkait dengan data dan informasi yang dibutuhkan oleh peneliti.

2) Observasi

Observasi dilakukan dengan mengamati kondisi yang sedang berlangsung pada lokasi organisasi. Kondisi tersebut dapat berupa media-media yang mendukung proses yang berhubungan dengan incident management, problem management, request fulfillment dan access management pada level service operation.

3) Studi dokumen 
Metode ini dilakukan oleh peneliti untuk menganalisis dokumen-dokumen prosedur apa saja yang dimiliki oleh pengelola layanan TI pada pemerintah Kota Madiun untuk kemudian dijadikan sebagai masukan dalam pembuatan SOP untuk pembuatan layanan Service Desk.

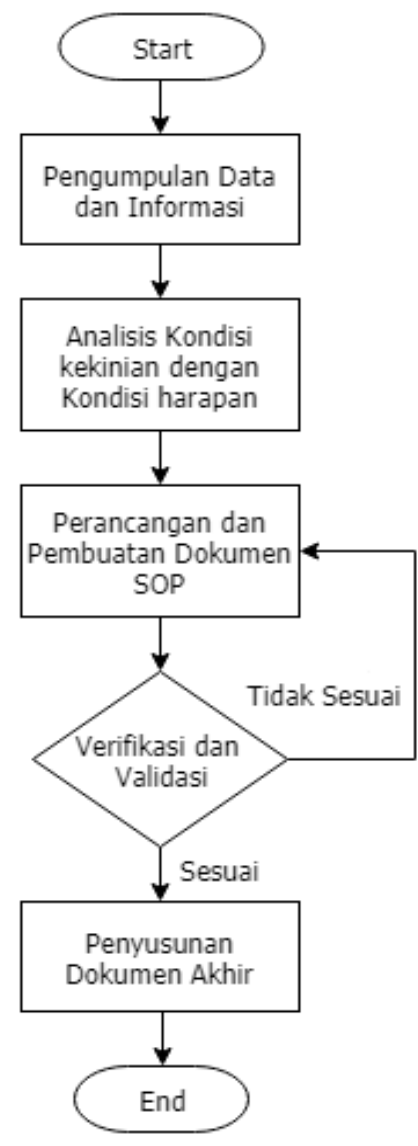

Gambar 1. Penelitian berfokus kepada aktivitas penyusunan prosedur dan formulir service desk

\subsection{Hasil Analisis Kesenjangan Kondisi Kekinian dan Kondisi Ideal pada Level Service Operation}

Bagian ini menjelaskan hasil yang didapatkan dari penelitian ini, dan pembahasan secara keseluruhan yang Analisis kesenjangan dilakukan dengan cara menganalisis kondisi kekinian pemerintah Kota Madiun berdasarkan aktivitas yang terdapat didalam standar acuan dan membandingkannya dengan kondisi ideal menurut ITIL V3 pada level service operation. Selanjutnya dilakukan pemetaan antara kondisi kekinian dan kondisi ideal untuk memudahkan dalam mengetahui kesenjangan yang terjadi pada pengelolaan layanan TI pemerintah Kota Madiun, sehingga analisis kesenjangan ini digunakan untuk mengetahui adanya ketidak sesuaian antara kondisi kekinian dengan kondisi ideal menurut standar acuan. Tabel 1 menunjukkan pemetaan hasil analisis kesenjangan dari semua proses dengan melakukan perbandingan antara kondisi kekinian dengan kondisi ideal menurut standar acuan ITIL V3. Hasil kesenjangan tersebut menunjukkan pentingnya prosedur dan formulir dalam menstandarisasi aktivitas yang seharusnya tersedia dalam mengelola operasional layanan TI. 
Tabel 1. Hasil analisis kesenjangan menunjukkan terbatasnya operasional layanan yang sesuai dengan standar ITIL V3

\begin{tabular}{|c|c|c|}
\hline Proses & Kekurangan & Usulan \\
\hline \multirow[t]{6}{*}{ Incident Management } & $\begin{array}{l}\text { Untuk prosedur pada proses incident } \\
\text { management dan request management dijadikan } \\
\text { dalam satu SOP }\end{array}$ & $\begin{array}{l}\text { Pembuatan ulang prosedur incident } \\
\text { management berdasarkan standar acuan } \\
\text { ITIL V3 }\end{array}$ \\
\hline & $\begin{array}{l}\text { Tidak adanya aktivitas pencatatan untuk } \\
\text { pelaporan masalah yang masuk }\end{array}$ & $\begin{array}{l}\text { Membuatkan template form pelaporan yang } \\
\text { dapat diisi oleh pihak pengelola layanan TI }\end{array}$ \\
\hline & $\begin{array}{l}\text { Tidak adanya aktivitas dalam pendefinisian } \\
\text { prioritas yang berdasarkan dampak dan urgensi }\end{array}$ & Melakukan pendefinisian prioritisasi \\
\hline & $\begin{array}{l}\text { Tidak adanya aktivitas perubahan status } \\
\text { penanganan layanan }\end{array}$ & Men \\
\hline & $\begin{array}{l}\text { Tidak adanya aktivitas penyimpan solusi } \\
\text { penanganan ke dalam media knowledge base }\end{array}$ & $\begin{array}{l}\text { penanganan layanan berdasarkan standar } \\
\text { acuan ITIL V3 }\end{array}$ \\
\hline & $\begin{array}{l}\text { yang digunakan sebagai kumpulan-kumpulan } \\
\text { atau histori solusi penanganan masalah yang } \\
\text { pernah dilakukan sebelumnya }\end{array}$ & $\begin{array}{l}\text { Menambahkan aktivitas knowledge base ke } \\
\text { dalam prosedur dan membuatkan template } \\
\text { form knowledge base }\end{array}$ \\
\hline \multirow[t]{7}{*}{ Request Fulfillment } & $\begin{array}{l}\text { Untuk prosedur pada proses incident } \\
\text { management dan request management dijadikan } \\
\text { dalam satu SOP }\end{array}$ & $\begin{array}{l}\text { Pembuatan ulang prosedur request } \\
\text { fulfillment berdasarkan standar acuan ITIL } \\
\text { V3 }\end{array}$ \\
\hline & $\begin{array}{l}\text { Tidak adanya aktivitas pencatatan untuk } \\
\text { pelaporan permintaan layanan yang diajukan }\end{array}$ & $\begin{array}{l}\text { Membuatkan template form pelaporan yang } \\
\text { dapat diisi oleh pihak pengelola layanan TI }\end{array}$ \\
\hline & Tidak adanya aktivitas dalam pendefinisian & dan pengguna layanan TI \\
\hline & prioritas yang berdasarkan dampak dan urgensi & Melakukan pendefinisian prioritisasi \\
\hline & $\begin{array}{l}\text { Tidak adanya aktivitas perubahan status } \\
\text { penanganan layanan }\end{array}$ & Menambahkan aktivitas perubahan status \\
\hline & $\begin{array}{l}\text { Tidak adanya aktivitas penyimpan solusi } \\
\text { penanganan ke dalam media knowledge base }\end{array}$ & $\begin{array}{l}\text { penanganan layanan berdasarkan standar } \\
\text { acuan ITIL V3 }\end{array}$ \\
\hline & $\begin{array}{l}\text { yang digunakan sebagai kumpulan-kumpulan } \\
\text { atau histori solusi penanganan masalah yang } \\
\text { pernah dilakukan sebelumnya }\end{array}$ & $\begin{array}{l}\text { Menambahkan aktivitas knowledge base ke } \\
\text { dalam prosedur dan membuatkan template } \\
\text { form knowledge base }\end{array}$ \\
\hline Problem Management & $\begin{array}{l}\text { Belum adanya prosedur yang secara khusus } \\
\text { menjelaskan terkait aktivitas penanganan } \\
\text { permasalahan TI }\end{array}$ & $\begin{array}{l}\text { Pembuatan prosedur problem management } \\
\text { berdasarkan standar acuan ITIL V3 }\end{array}$ \\
\hline Access Management & $\begin{array}{l}\text { Belum adanya prosedur yang secara khusus } \\
\text { menjelaskan terkait aktivitas pemenuhan } \\
\text { permintaan akses pengguna }\end{array}$ & $\begin{array}{l}\text { Pembuatan prosedur access management } \\
\text { berdasarkan standar acuan ITIL V3 }\end{array}$ \\
\hline
\end{tabular}

\subsection{Perancangan Standard Operating Procedure Beserta Formulirnya}

Penyusunan standard operating procedure (SOP) mengacu pada Peraturan Menteri Pendayagunaan Aparatur Negara dan Reformasi Birokrasi Republik Indonesia Nomor 35 tahun 2012. Dalam penyusunan format SOP didasarkan pada tujuan pembuatan SOP serta tidak adanya format baku dalam penyusunan format SOP [14]. Setelah dokumen SOP selesai dibuat maka akan dilakukan tahap verfifkasi dan tahap validasi untuk mengetahui apakah dokumen SOP sesuai dengan kriteria yang dibutuhkan oleh organisasi. Tabel 2 menunjukkan hasil penyusunan SOP beserta formulir yang dihasilkan dengan menggunakan kode untuk setiap SOP dan formulir. Total terdapat 4 (empat) SOP dan 8 (delapan) formulir yang dihasilkan dari penelitian ini. Seluruh SOP dan formulir disusun berdasarkan analisis kesenjangan proses yang telah dipaparkan pada subbab sebelumnya. 
Tabel 2. SOP dan formulir yang menunjukkan proses-proses yang terstandar dalam pengelolaan operasional layanan TI

\begin{tabular}{|c|c|c|c|}
\hline Nomor SOP & Nama SOP & Nomor Formulir & Nama Formulir \\
\hline \multirow[t]{4}{*}{ SOP-Dinkominfo-001 } & \multirow[t]{4}{*}{ SOP Penanganan Insiden } & FRM- Service Desk -001 & Formulir Pelaporan \\
\hline & & FRM- Service Desk -002 & Formulir Pencatatan \\
\hline & & FRM- Dinkominfo -004 & Formulir Survey Kepuasaan Masalah \\
\hline & & FRM- Dinkominfo -006 & Formulir Eskalasi \\
\hline \multirow[t]{5}{*}{ SOP-Dinkominfo-002 } & \multirow{5}{*}{$\begin{array}{l}\text { SOP Pemenuhan Permintaan } \\
\text { Layanan }\end{array}$} & FRM- Service Desk -001 & Formulir Pelaporan \\
\hline & & FRM- Service Desk -002 & Formulir Pencatatan \\
\hline & & FRM- Dinkominfo -005 & $\begin{array}{l}\text { Formulir Survey Kepuasaan } \\
\text { Permintaan }\end{array}$ \\
\hline & & FRM- Dinkominfo -006 & Formulir Eskalasi \\
\hline & & FRM- Dinkominfo -007 & $\begin{array}{l}\text { Surat Permohonan Permintaan } \\
\text { Layanan }\end{array}$ \\
\hline SOP-Dinkominfo-003 & SOP Pengelolaan Permasalahan & FRM- Dinkominfo -003 & Formulir Tambah Artikel \\
\hline \multirow[t]{5}{*}{ SOP-Dinkominfo-004 } & \multirow{5}{*}{$\begin{array}{l}\text { SOP Pemenuhan Permintaan } \\
\text { Akses }\end{array}$} & FRM- Service Desk -001 & Formulir Pelaporan \\
\hline & & FRM- Service Desk -002 & Formulir Pencatatan \\
\hline & & FRM- Dinkominfo -005 & $\begin{array}{l}\text { Formulir Survey Kepuasaan } \\
\text { Permintaan }\end{array}$ \\
\hline & & FRM- Dinkominfo -006 & Formulir Eskalasi \\
\hline & & FRM- Dinkominfo -008 & Surat Permohonan Permintaan Akses \\
\hline
\end{tabular}

\subsection{Penyusunan Dokumen Akhir}

Pada bagian ini akan dipaparkan penjelasan mengenai salah satu prosedur yang tertera dalam SOP incident management. Dalam melakukan penyusunan SOP penanganan insiden peneliti menggunakan panduan SOP menurut Peraturan Menteri Pendayagunaan Aparatur Negara dan Reformasi Birokrasi Republik Indonesia Nomor 35 Tahun 2012 Tentang Pedoman Penyusunan Standar Operasional Prosedur Administrasi Pemerintahan. Di dalam SOP, model prosedur akan dijabarkan dalam bentuk flowchart dikarenakan terdapat banyak aktivitas dan keputusan yang saling berkaitan seperti terlihat pada Gambar 2 (a) sampai dengan (f). Gambar tersebut menunjukkan bahwa aktivitas dalam prosedur menunjukkan apa yang perlu dilakukan oleh pelaksana dengan memperhatikan mutu baku (syarat dan waktu) yang ditentukan.

Salah satu formulir yang dihasilkan melalui penelitian ini adalah Formulir Survey Kepuasaan Masalah (FRM- SERVICE DESK -004). Formulir ini diisi oleh klien yang telah melaporkan masalah kepada Dinkominfo Pemerintahan Kota Madiun setelah dilakukan penyelesaian penanganan masalah oleh Dinkominfo Pemerintahan Kota Madiun guna mengetahui performa pelayanan yang dilakukan. Gambar 3 menunjukkan formulir survei kepuasan tersebut. 


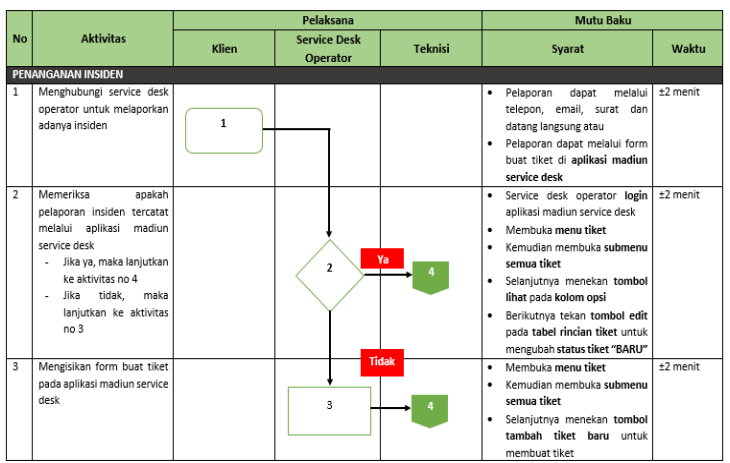

(a)

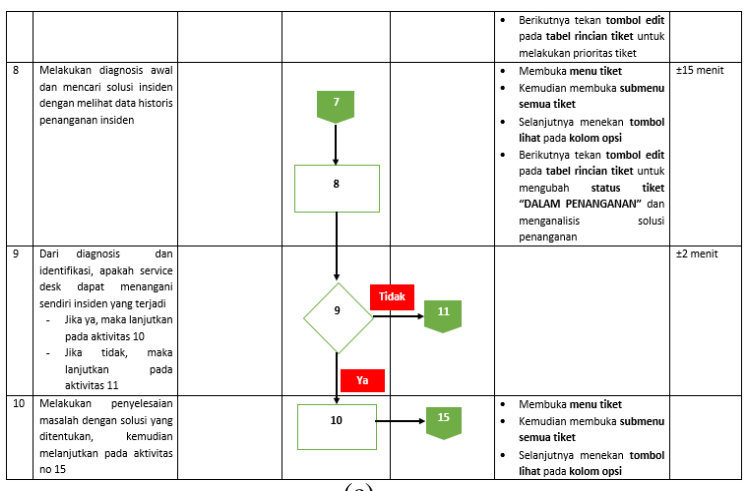

(c)

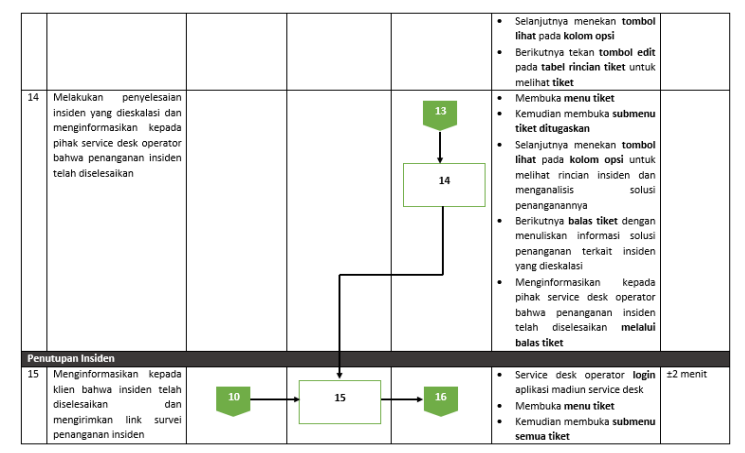

(e)

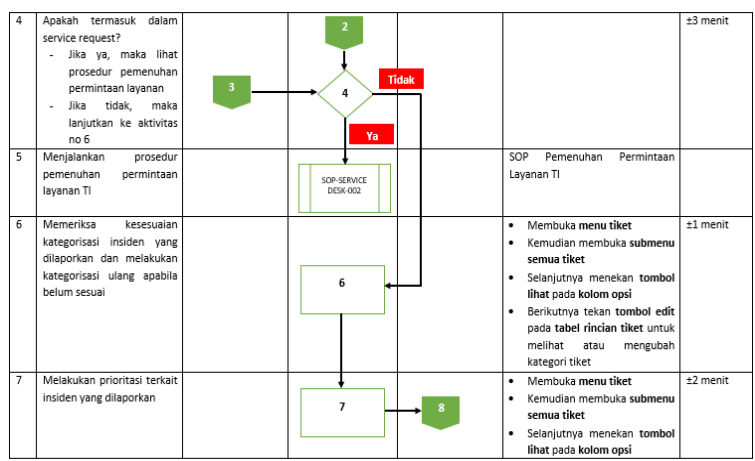

(b)

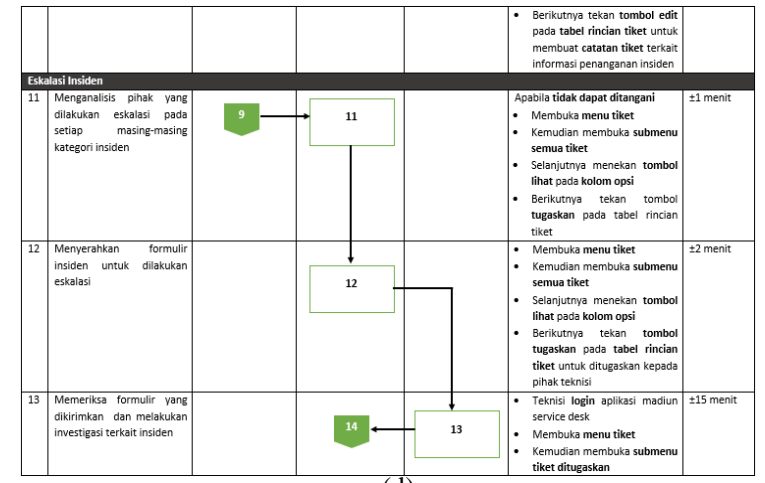

(d)

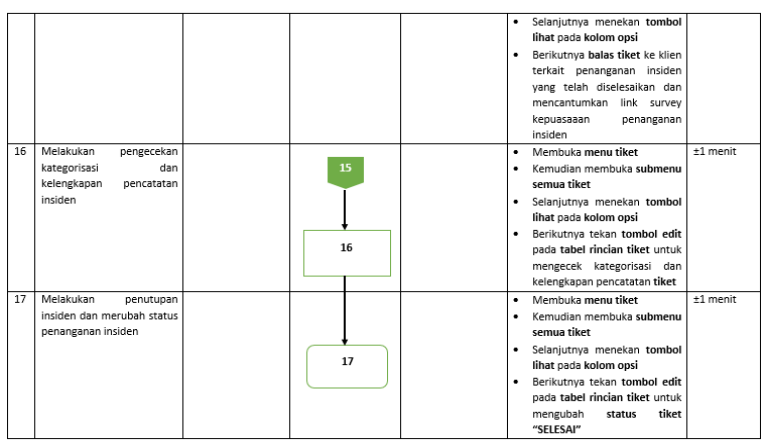

(f)

Gambar 2. SOP Penanganan Insiden menunjukkan serangkaian langkah dalam mengelola insiden layanan TI 


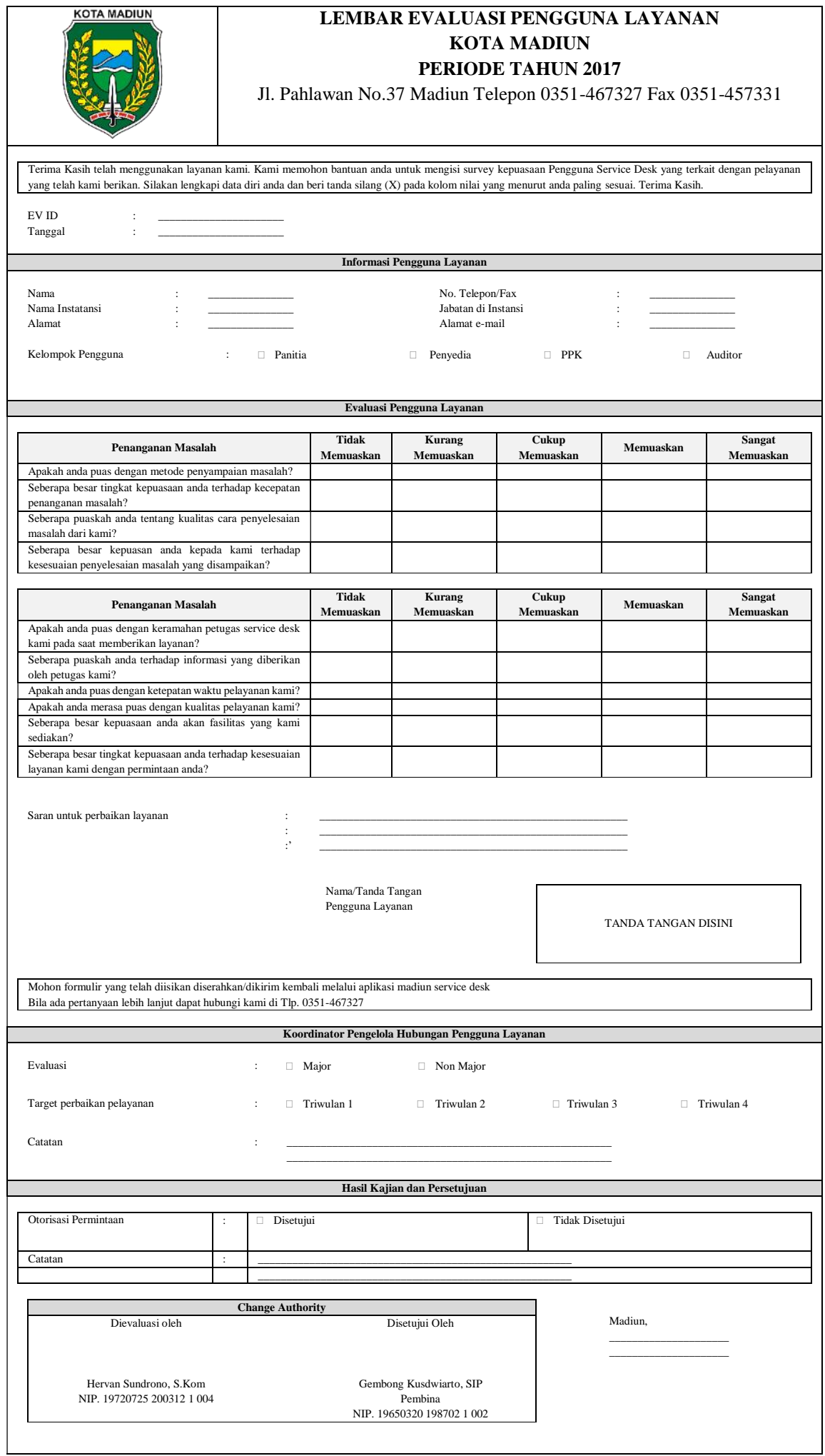

Gambar 3. Formulir survei diberikan setelah pengguna terpenuhi layanannya 


\section{Kesimpulan}

Pada bagian ini dipaparkan hasil simpulan dari penelitian yang dilakukan. Selain itu dipaparkan saran yang bermanfaat untuk penelitian di masa yang akan datang.

\subsection{Simpulan}

Berdasarkan hasil analisis kesenjangan yang telah dilakukan antara kondisi eksiting pada proses pengelolaan layanan TI pemerintah Kota Madiun dengan kondisi ideal menurut proses incident management, request fulfillment, access management dan problem management pada kerangka kerja ITIL V3, sebagian besar hasil yang diperoleh untuk setiap proses yang dilakukan oleh pihak pengelola layanan TI (dinkominfo dan OPD yang mempunyai staff TI) yaitu sedikitnya aktivitas pencatatan mengenai alur pelaporan insiden, permintaan layanan, permintaan akses dan identifikasi insiden berulang.

Didapatkan empat usulan prosedur berdasarkan standar acuan ITIL V3 yaitu prosedur penanganan insiden, prosedur pemenuhan permintaan layanan, prosedur pemenuhan permintaan akses dan prosedur penanganan permasalahan untuk layanan Service Desk pemerintah Kota Madiun. Di dalam masing-masing prosedur terdapat formulir yang mendukung pelaksanaan prosedur. Untuk formulir terdiri dari delapan yaitu formulir pelaporan, formulir pencatatan, formulir tambah artikel, formulir survey kepuasan masalah, formulir survey kepuasan permintaan, formulir eskalasi, surat permohonan permintaan layanan dan surat permohonan permintaan akses. Diharapkan dalam pembuatan SOP ini dapat memberikan standarisasi terhadap pihak pengelola layanan TI (dinkominfo dan OPD yang mempunyai staff TI).

\subsection{Saran}

Beberapa saran untuk keberlanjutan penelitian ini antara lain sebagai berikut.

1) Dalam penelitian ini, dilakukan pembatasan hanya untuk proses incident management, request fulfillment, access management dan problem management sedangkan untuk proses event management tidak termasuk dalam pembuatan SOP layanan Service Desk pemerintah Kota Madiun

2) Penelitian tidak melakukan pemantauan terhadap penggunaan SOP di dalam kegiatan sehari-hari sehingga untuk penelitian selanjutnya dapat dilakukan penilaian kinerja dan evaluasi terhadap penerapan SOP.

\section{Daftar Rujukan}

[1] D. Admin, "Integrasikan E-Budgetting, E-Planning dan E-Kontrak, Kota Madiun Menuju Smart City,” Pemerintah Kota Madiun, [online]. Available: http://madiunkota.go.id/index.php/2018/01/11/integrasikan-e-budgetting-e-planning-dan-e-kontrak-kotamadiun-menuju-smart-city/. [Diakses: 11-Jan-2018].

[2] "What is Service Desk? - Definition from WhatIs.com," SearchWindowsServer. [Online]. Available: http://searchwindowsserver.techtarget.com/definition/service-desk. [Accessed: 13-Mar-2018].

[3] FEMA, "Developing Effective Standard Operating Procedures for Fire and EMS Departments," 1999.

[4] S. K. Jain, "Standard Operating Procedures (SOP) - Back Bone of Pharmaceutical Industries," vol. 6, no. 5, 2008.

[5] J. v. Bon, Foundation of IT Service Management Based ITIL V3, Van Haren Publisher.

[6] "IT Service Management (ITSM) | Standardisation Testing and Quality Certification Directorate." [Online]. Available: http://www.stqc.gov.in/content/it-service-management-itsm. [Diakses: 13-Mar-2018].

[7] "7 Examples of a Single Point of Contact," Simplicable. [Online]. Available: https://simplicable.com/new/single-point-ofcontact. [Diakses: 13-Mar-2018].

[8] T. D. Susanto, Manajemen Layanan Teknologi Informasi, Surabaya.

[9] W.R. Wicaksana, T.D. Susanto, A. Herdiyanti, 2016. Pembuatan Standar Operasional Prosedur (SOP) Manajemen Akses Untuk Aplikasi E-Performance Bina Program Kota Surabaya Berdasarkan Kerangka Kerja ITIL V3 Dan ISO 27002. Jurnal SISFO Vol 6 (1), Surabaya: Departemen SI - ITS.

[10] A.F. Rizky, T.D. Susanto, A. Herdiyanti, 2017. Pembuatan Prosedur Operasional Standar Pengelolaan Insiden pada Government Resources Management Systems Kota Surabaya Berdasarkan ITIL V3. Jurnal SISFO Vol 6 (2), Surabaya: Departemen SI ITS. 
[11] Guidance for Preparing Standard Operating Procedures (SOPs). Wangshinton DC, 2007.

[12]T. Atmoko, "Standar Operasional Prosedur (SOP) dan Akutanbilitas Kinerja Instansi Pemerintahan." [Online]. Available: http://e-dokumen.kemenag.go.id/files/BX32jRZz1284857253.pdf Diakses: 13-Mar-2018].

[13] M. Budiharjo Panduan Praktis Menyusun SOP, Yogyakarta: Gadjah Mada University Press, 2014.

[14]P. A. NEGARA, D. R. BIROKRASI, and R. INDONESIA, Pedoman Penyusunan Standar Operasional Prosedur Administrasi Pemerintahan. Jakarta, 2012. 
ZulaikahEffendiet al. / Jurnal SISFO Vol.08 No.02 (2019) 117-128

Halaman ini sengaja dikosongkan 
